\title{
APRESENTAÇÃO: A POLÍTICA EXTERIOR DO BRASIL
}

\author{
Amado Luiz Cervo ${ }^{1}$
}

Os estudiosos da política exterior do Brasil transitaram da antiga história diplomática, pela história da política exterior, para chegar à inserção internacional do país. $O$ conceito de inserção envolve três componentes: a negociação diplomática, a política exterior que lhe agrega valores e interesses nacionais e o movimento dos atores não governamentais que agem externamente em busca de interesses específicos. A partir desse conceito de inserção, a análise paradigmática permite distinguir quatro impulsos históricos, os chamados paradigmas, a condicionar a funcionalidade da política exterior: trata-se dos modelos primário-exportador da Independência a 1930, desenvolvimentista de 1930 a 1989, o neoliberalismo da década de 1990 e o que denominamos de Estado logístico, no século XXI.

Quando a Universidade incorpora a área de ensino e pesquisa de relações exteriores do país, desde os anos 1970, multiplicam-se os estudos, até então reservados antes de tudo à indagação do corpo diplomático. Embora seja possível fazê-lo, raramente os estudiosos isolam em suas análises um dos três componentes da inserção. Isso ocorre porque, nessas últimas décadas, revelaram-se claros e perceptíveis não somente os nexos estreitos entre diplomacia, política exterior e relações internacionais do país, como também a ascensão da sociedade e a nova relação entre sociedade e Estado.

\footnotetext{
1 Professor Titular de História das Relações Internacionais da Universidade de Brasília. Emérito. Pesquisador Sênior do Conselho Nacional de Desenvolvimento Científico e Tecnológico-CNPq (alcervo@unb.br).
} 
O desenvolvimento a promover submete a si o impulso nacional desde a ascensão de Getúlio Vargas, nos anos 1930. O desenvolvimento haveria de ser tocado pela via da industrialização como ratio de longo prazo, mas foi concebido diversamente pelos dirigentes ao longo do tempo, quanto a mecanismos, etapas, modo de relacionar interno e externo e maturidade do processo. Liberais de todas as décadas concebiam o desenvolvimento, prioritariamente, como responsabilidade externa de nações mais avançadas, que haveriam de acoplar-se ao desígnio nacional com capitais, empreendimentos e tecnologias. Nacionalistas de todos os tempos o concebiam, prioritariamente, como responsabilidade interna, a ser tocado por meio de insumos próprios. Dependentistas e independentistas dividiam desse modo a opinião em duas correntes, as quais disputavam o poder, ou seja, o Estado.

Extraindo força dessas duas correntes, a liberal e a autonomista, a formação nacional do Brasil resultou equilibrada, liberal e nacional, aberta e autônoma, vinculada ao mundo e de curso próprio. Diplomacia, política exterior e relações internacionais seguiram condicionando-se crescentemente, ao longo das décadas, de tal sorte que a inserção resultasse com a marca do equilíbrio.

Um dos primeiros requisitos desse modelo haveria de ser a autonomia da política exterior, sem a qual a estratégia de desenvolvimento escaparia do controle nacional. Concebida como autonomia decisória, já nos anos 1930, a política exterior pautou-se, não obstante, pela cooperação com o exterior e pelo não-confrontacionismo. Por óbvio, liberais tendiam à subserviência decisória e à inserção dependente, tanto quanto nacionalistas ao confronto e ao isolamento. Mas a filosofia do equilíbrio acabou prevalecendo ao longo do tempo. Em suma, o cálculo político haveria de incluir a reciprocidade dos benefícios da inserção ao considerar interesses próprios e alheios.

O modelo brasileiro de inserção, à base dessa visão de relações internacionais em que as nações cooperam entre si, não descarta por certo o inevitável choque de interesses, cuja superação, conciliação ou não é posta a cargo da negociação diplomática. Se a gerência do nexo entre interesses próprios e alheios, particularmente econômicos, afigurou-se historicamente difícil na experiência brasileira, mais difícil ainda seria o intento de conciliar valores entre as nações, próprio da visão brasileira de mundo. Ocidente, socialismo, capitalismo, choque de civilizações, entre outros elementos, imiscuíram suas dimensões ideológicas e culturais no pensamento e no processo decisório 


\section{Amado Luiz Cervo}

nacionais como insumos e como desafios. Por vezes tais insumos aprofundaram a cisão entre liberais e independentistas, como testemunham as controvérsias entre intelectuais e dirigentes nos anos 1960, controvérsias que afloram novamente na virada do milênio, quando da experiência neoliberal.

A identidade nacional brasileira, etnicamente heterogênea e culturalmente plural, de nação com desigualdades sociais enormes e com ambição de desenvolvimento, serviu de matriz da conduta externa. Convivência de diferenças e pacifismo resultaram dessa relação entre identidade nacional e inserção internacional, como valores, bens em si. Contudo, gerenciar valores em política internacional revelou-se conturbação ainda maior do que gerenciar interesses materiais ou de segurança. O global é povoado por imposições de valores próprios entendidos como benesses sistêmicas por governos e sociedades onde se configuram identidades nacionais diferenciadas.

A política exterior do Brasil segue, dizíamos anteriormente, rumo à maturidade da inserção internacional. Nesse sentido, o século XXI constitui ponto de chegada avançado de um país novo, a procura do próprio destino. Quais os traços do modelo brasileiro de inserção internacional no século XXI?

Nada de neodesenvolvimentismo se observa no Brasil do século XXI, se considerado esse paradigma de retorno/avanço à luz da experiência argentina, feita muito mais de retornos aos desvios exacerbados do desenvolvimentismo: reestatização, protecionismo, instabilidade monetária, isolamento econômico e financeiro. A América Latina no século XXI não realiza o consenso de um paradigma, como fez desde a independência até o ano 2000. A ascensão internacional do Brasil no século XXI se descola da vizinhança e se deve precisamente ao avanço rumo à maturidade sistêmica, que incorpora melhor os benefícios do desenvolvimento, agrega-lhe a conveniente interdependência do liberalismo, mas prolonga a autonomia inerente ao cálculo estratégico em política exterior, tudo envolto pelo equilíbrio.

$O$ condicionante fundamental da inserção internacional do Brasil no século XXI é a emergência da sociedade. Ao longo de seis décadas, cabia ao Estado conceber e ditar a uma sociedade quase inerte a natureza e os requisitos do interesse nacional, bem como os valores da identidade, e arrastar tal sociedade rumo ao desenvolvimento. O paradigma neoliberal dos anos 1990, enfraquecendo o Estado e recorrendo à subserviência externa, induziu resultado 
benéfico para a formação nacional. O século XXI amadurece esta evolução, que tira forças do passado, uma vez que tendências diversas em conceber e executar a política sempre se fizeram presentes na tradição nacional. Assim emerge a sociedade, com segmentos organizados, lideranças ativas, interesses específicos a realizar, e com vontade de movimento.

A funcionalidade da política exterior brasileira no século XXI é modificada em sua essência. Novo padrão de relacionamento se estabelece entre Estado e sociedade, nunca antes cultivado com tal intensidade. O nexo envolve os três componentes da inserção internacional: diplomacia, política exterior e relações internacionais. $O$ Estado transfere poder e responsabilidade a atores não governamentais quanto ao desenvolvimento a promover e cede parte da decisão estratégica em política exterior.

À época do desenvolvimentismo, cabia fundamentalmente ao Estado o comando da diplomacia, da política exterior e das relações internacionais. À época do neoliberalismo, entregava-se esse comando às forças do mercado. No século XXI, a inovação consiste em trazer a sociedade para dentro do Estado, cuja funcionalidade consiste em administrar pelo alto os interesses dos segmentos que agem externamente, interesses por vezes conflitantes, e em agregá-los no superior interesse nacional. A esse novo padrão chamamos de Estado logístico, visto não ser mais Estado empresário, tampouco Estado omisso, mas apenas condutor da sociedade em busca de oportunidades externas ou mesmo inventor de oportunidades, além de responsável pela harmonização de seus segmentos.

A conduta diplomática em tempo de Estado logístico orienta-se pelos princípios da reciprocidade de benefícios entre as nações no campo da negociação multilateral e pela consolidação de parcerias bilaterais, visto que estas parcerias também estendem os interesses e o poder nacional. $O$ desfile de parcerias estáveis e apreciadas, tanto pelo lado econômico quanto político e geopolítico, adorna o tempo das relações internacionais do Brasil: Inglaterra, Estados Unidos, Argentina, Alemanha, Itália, França, Japão, China, Portugal, Espanha, entre outros, que incluem toda a vizinhança.

A integração regional converte-se, no século XXI, em instrumento de apoio à vocação globalista do país. Esta se realiza por meio da influência sobre o cenário internacional com o fim de transformar as regras da ordem e por meio de vínculos mais robustos de interdependência global, especialmente pela via da 


\section{Amado Luiz Cervo}

expansão para fora das empresas brasileiras. A integração conserva, contudo, como perene, a função de manter e cultivar o clima de entendimento político na América do Sul, talvez na América Latina, visto constituir a vizinhança uma reserva estratégica necessária para se alcançar o global como desígnio.

Em três domínios da ação externa, a evolução para a maturidade sistêmica produz os melhores efeitos. Por um lado, a integração regional constrói o ambiente de entendimento político e de relações cordiais, embora, diante da diversidade dos desígnios nacionais e dos modelos de inserção na vizinhança, acabe sacrificando o projeto brasileiro de integração produtiva que viria acoplado à internacionalização econômica do país. Em segundo lugar, o reforço dos vínculos com os países emergentes, entre os quais o Brasil se julga localizado. $\mathrm{O}$ cálculo dos benefícios contamina dirigentes e lideranças sociais. Os países emergentes são mais propensos do que os países do velho núcleo capitalista avançado a considerar a reciprocidade de benefícios nas regras que compõem a ordem internacional; são mais inclinados à superação de assimetrias entre as nações do que os mesmos países avançados; enfim, comungam o conceito de segurança internacional que visa substituir a estratégia da violência implementada desde a Segunda Grande Guerra pela OTAN pela estratégia da negociação conciliadora diante dos conflitos .

O resultado mais palpável da evolução para a maturidade consiste, entretanto, na internacionalização da economia brasileira. Movimento tímido até por volta de 2005, reforça-se posteriormente e desloca-e geograficamente: da América do Sul à América do Norte, à África e à Europa, capitais e empresas brasileiras se movem e estabelecem a interdependência econômica em condições de operacionalidade sistêmica.

Os limites de eficiência do modelo brasileiro de inserção internacional são criados, sobretudo, internamente, na forma de obstáculos à realização de resultados. No domínio da segurança, o abandono do projeto de autonomia militar concebido nos anos 1970 e o descaso pela indústria bélica. No domínio de aproveitamento de investimentos internos e externos acumulam-se os maiores entraves postos à evolução para a maturidade: carga tributária excessiva, juros elevados, burocracia inchada e infraestrutura precária. Na esfera da relação entre Estado e sociedade, o maior obstáculo consiste na baixa inovação tecnológica derivada da escassez de estímulos públicos voltados a uma educação 
para a inovação e da tradicional baixa propensão do empresariado brasileiro em inovar, excetuado o agronegócio. Tais constrangimentos tendem a enfraquecer tanto o nível de competitividade dos sistemas produtivo e de serviço em âmbito interno quanto o comércio exterior e a expansão para fora de empreendimentos brasileiros. 